\title{
Morphological evidence for uncontrolled proteolytic activity during the ovulatory process in indomethacin-treated rats
}

\author{
F. Gaytán ${ }^{1}$, E. Tarradas ${ }^{1}$ C. Morales ${ }^{2}$, C. Bellido ${ }^{1}$ \\ and J. Eugenio Sánchez-Criado ${ }^{1}$ \\ ${ }^{1}$ Department of Cell Biology, Physiology and Immunology; and ${ }^{2}$ Department of Pathology, \\ School of Medicine, University of Cordoba, Spain
}

\begin{abstract}
The ovulatory process in cyclic rats was studied after prostanoid synthesis was blocked using indomethacin. Animals were injected at 12:00 $\mathrm{h}$ in pro-oestrus with $1.0 \mathrm{mg}$ indomethacin or vehicle (olive oil) and killed at 18:30 $\mathrm{h}$ in pro-oestrus, at 02:00, 09:00 and 19:00 $\mathrm{h}$ in oestrus and at 09:00 $\mathrm{h}$ in metoestrus. Additional rats injected with 0.5 or $4.0 \mathrm{mg}$ indomethacin were killed at 09:00 $\mathrm{h}$ in oestrus. No differences in either morphology or serum LH concentrations were found between vehicle or indomethacin-treated rats at 18:30 $\mathrm{h}$ in pro-oestrus. However, from 02:00 $\mathrm{h}$ in oestrus onward, the process of follicle rupture was altered considerably in indomethacintreated rats, irrespective of the dose. Early vascular changes, observed in control rats at the apex of the follicle,
\end{abstract}

\section{Introduction}

During ovulation, the ovarian tissues located between the oocyte and the ovarian surface (including two basement membranes and the collagenous tissue of the theca and tunica albuginea) have to be degraded. The current view of ovulation is that the preovulatory LH surge initiates an inflammatorylike reaction that leads ultimately to the activation of tissue matrix-degrading enzymes. The subsequent degradation of collagenous tissue at the apex of the follicle allows release of the cumulus containing the oocyte, under the force of a modest, but effective, intrafollicular pressure (Espey, 1980, 1994, 1998; Tsafriri et al., 1993; Espey and Lipner, 1994).

Eicosanoids, the active products of arachidonic acid metabolism, have been widely considered to play a key role in ovulation (Brännström and Janson, 1991; Tsafriri et al., 1993; Espey, 1994; Espey and Lipner, 1994). Evidence for involvement of prostanoids in the ovulatory process is derived, at least in part, from the repeated observation that indomethacin, a powerful inhibitor of cyclooxygenase, inhibits ovulation in several species (Brännström and Janson, 1991; Tsafriri et al., 1993; Espey and Lipner, 1994). In rats, indomethacin blocks ovulation over a broad period of time, from $10 \mathrm{~h}$ before to $13 \mathrm{~h}$ after hCG administration (Tanaka et al., 1992).

Email: fi1begac@uco.es were absent in indomethacin-treated rats. In some follicles, disruption of the theca layers, invasion of the perifollicular tissue by granulosa cells and follicular fluid, and release of the oocyte to the ovarian interstitium were observed at 02:00 $\mathrm{h}$ in oestrus. A small number of follicles ruptured at the ovarian surface. Furthermore, invasion of interstitial tissue, rupture of blood vessel walls, production of emboli of granulosa cells and follicular fluid, and inflammatory reactions were observed in oestrus and metoestrus. The results of the present study demonstrate uncontrolled proteolytic activity, and indicate that abnormal follicle rupture (but not inhibition of follicle rupture) is responsible for ovulation failure in indomethacin-treated rats.

The anti-ovulatory action of indomethacin seems not to be due to secondary effects via other organs. Experiments with ovaries perfused in vitro (Hamada et al., 1977; Holmes et al., 1983) demonstrated that indomethacin blocks ovulation via direct actions on the ovary. However, the mechanisms of the anti-ovulatory effect of indomethacin are not known. Biochemical studies on proteolytic activity also provided contradictory results. Whereas some studies reported inhibition of collagenolytic activity in indomethacintreated animals (Reich et al., 1985a, 1991; Murdoch and McCormick, 1991), other studies found that collagenolytic activity was not affected (Curry et al., 1986; Tanaka et al., 1992).

In spite of the large number of studies using indomethacin to block ovulation, morphological studies are scarce. Detailed structural studies in mice (Downs and Longo, 1982, 1983), rats (Parr, 1974) and rabbits (Espey et al., 1981) have been limited to the apex of the follicle, and have also provided contradictory results.

The blocking effect of indomethacin on follicle rupture in most cases has been deduced indirectly by counting oocytes in the oviducts on the morning of oestrus or in the perfusion chamber in studies in vitro (Shimada et al., 1983; Reich et al., 1985a; Mikuni et al., 1998). However, Osman and Dullaart (1976) suggested that the processes of follicle rupture (that is, the breakdown of the follicle wall) and ovulation (that is, the release of mature oocytes from the 
ovary) may be dissociated in indomethacin-treated rats. These authors reported the presence of eggs in the dense extrafollicular tissue, beneath the tunica albuginea, close to luteinized follicles in oestrus. This finding has been scarcely considered in the literature, and has been interpreted thereafter as a consequence of the differential effects of indomethacin on collagenase activities; the undisturbed action of collagenase IV would allow disruption of the basement membrane and escape of the oocyte from the follicular antrum, whereas inhibition of interstitial collagenase would prevent degradation of the collaganous tissue of the theca and tunica albuginea (Reich et al., 1991; Tsafriri et al., 1993).

In this context, the morphological characteristics of mature follicles during the ovulatory process in indomethacintreated rats are not clear. The aim of the present study was to analyse the morphological changes in the ovaries of indomethacin-treated cyclic rats during the periovulatory period to help clarify the still undefined role of prostanoids in ovulation.

\section{Materials and Methods}

Adult cyclic Wistar rats were maintained under controlled light (14 h light:10 h dark, lights on at 05:00 h) and temperature conditions, and had free access to rat chow and tap water. Vaginal smears were taken each day, and only animals displaying at least two consecutive 4 day oestrous cycles were used. Experiments were performed according to the Guide for Care and Use of Laboratory Animals, and were approved by the Ethical Committee of the University of Córdoba.

Rats were injected s.c. at 12:00 $\mathrm{h}$ in pro-oestrus with 0.5 , 1.0 or $4.0 \mathrm{mg}$ indomethacin (IM, Sigma Chemical Co., St Louis, MO) in olive oil or vehicle $(200 \mu \mathrm{l})$. Rats injected with $1.0 \mathrm{mg}$ indomethacin or with vehicle were killed at 18:30 $\mathrm{h}$ in pro-oestrus (ten animals per group), at 02:00, 09:00 and 19:00 $\mathrm{h}$ in oestrus and at 09:00 $\mathrm{h}$ in metoestrus (five animals per group). Rats injected with 0.5 and $4.0 \mathrm{mg}$ indomethacin were killed at 09:00 $\mathrm{h}$ in oestrus (five and three animals per group, respectively).

Ovaries were dissected and fixed in Bouin-Hollande's fluid for at least $24 \mathrm{~h}$ and processed for embedding in paraffin wax. Serial sections $(5 \mu \mathrm{m})$ were cut and stained with alcian blue-haematoxylin and eosin, and scored systematically under the microscope. The percentages of the different types of luteinized follicles-corpora lutea were determined at 09:00 $\mathrm{h}$ in oestrus, by two independent, blind to the treatment, observers. Inter-observer variation was negligible.

LH concentrations, at the expected time of the preovulatory surge (18:30 $\mathrm{h}$ on the evening of proestrus in our colony; Gaytán et al., 1997a), were determined by radioimmunoassay in rats injected with $1.0 \mathrm{mg}$ indomethacin or vehicle (ten animals per group) in trunk blood collected at the time of death, using the microassay method described by Sánchez-Criado et al. (1993).

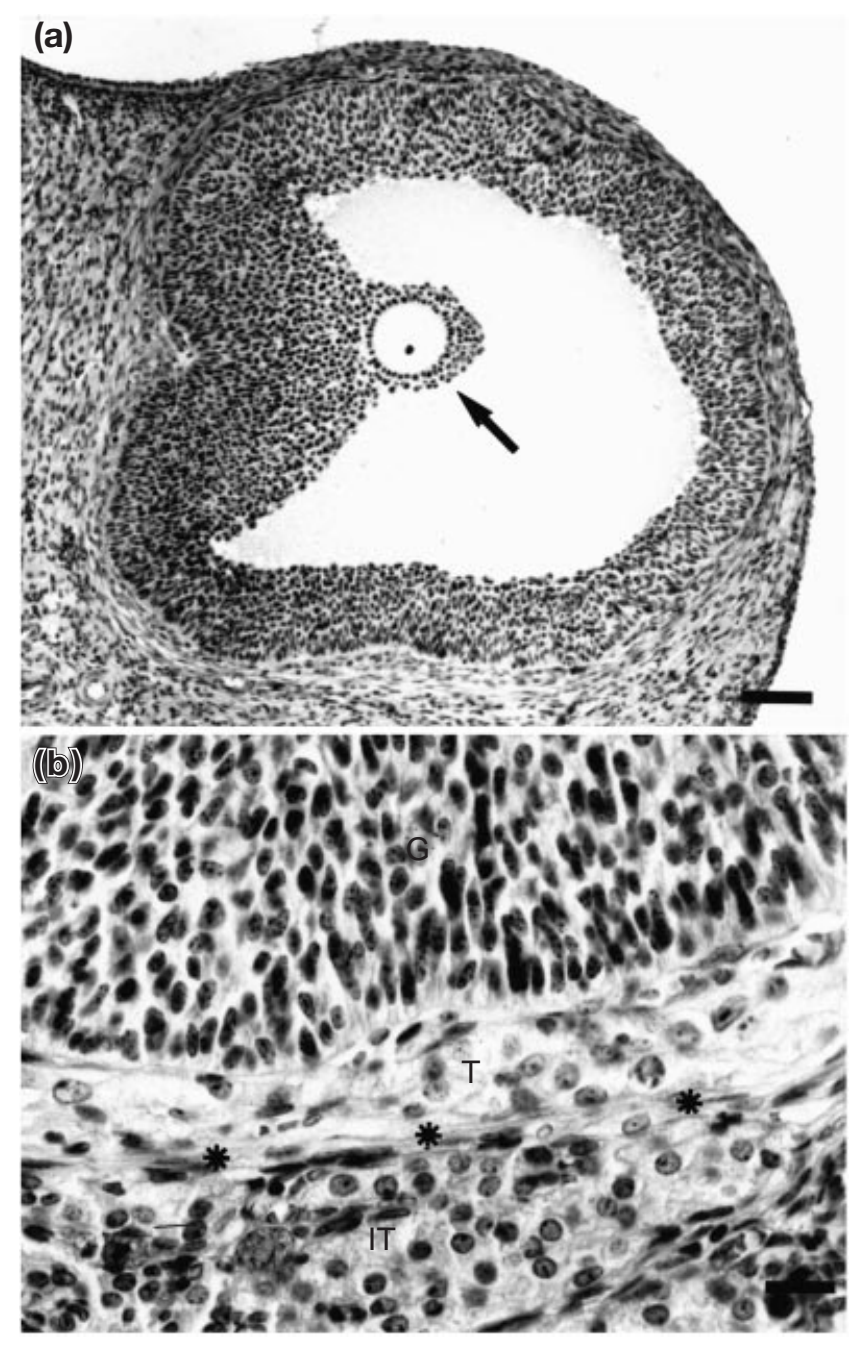

Fig. 1. (a) Preovulatory follicle from a vehicle-treated rat, at $18: 30 \mathrm{~h}$ in pro-oestrus, showing the cumulus (arrow) containing the oocyte, which is in the germinal vesicle stage. (b) Detail of the follicle wall, showing the granulosa (G), theca interna (T) and theca externa (asterisks). IT: interstitial tissue. Scale bars represent (a) 80 and (b) $25 \mu \mathrm{m}$.

\section{Results}

In control rats, preovulatory follicles showed the expected maturational changes (Vermeiden and Zeilmaker, 1974; Gaytán et al., 1997b). At 18:30 h on the evening of prooestrus, the oocyte was in the germinal vesicle stage, the cumulus was compact, and the granulosa cell layer was well organized (Fig. 1). Morphological differences were not found in indomethacin-treated rats, and LH concentrations, at the expected time of the preovulatory surge, were also equivalent $\left(28.3 \pm 5.0\right.$ versus $26.5 \pm 5.0 \mathrm{ng} \mathrm{ml}^{-1}$ in control and indomethacin-treated rats, respectively; mean \pm SEM for $n=10)$.

At $02: 00 \mathrm{~h}$ in oestrus, preovulatory follicles of control rats showed the characteristic $\mathrm{LH}$-induced changes. The cumulus was dispersed and the oocyte was free in the antral 

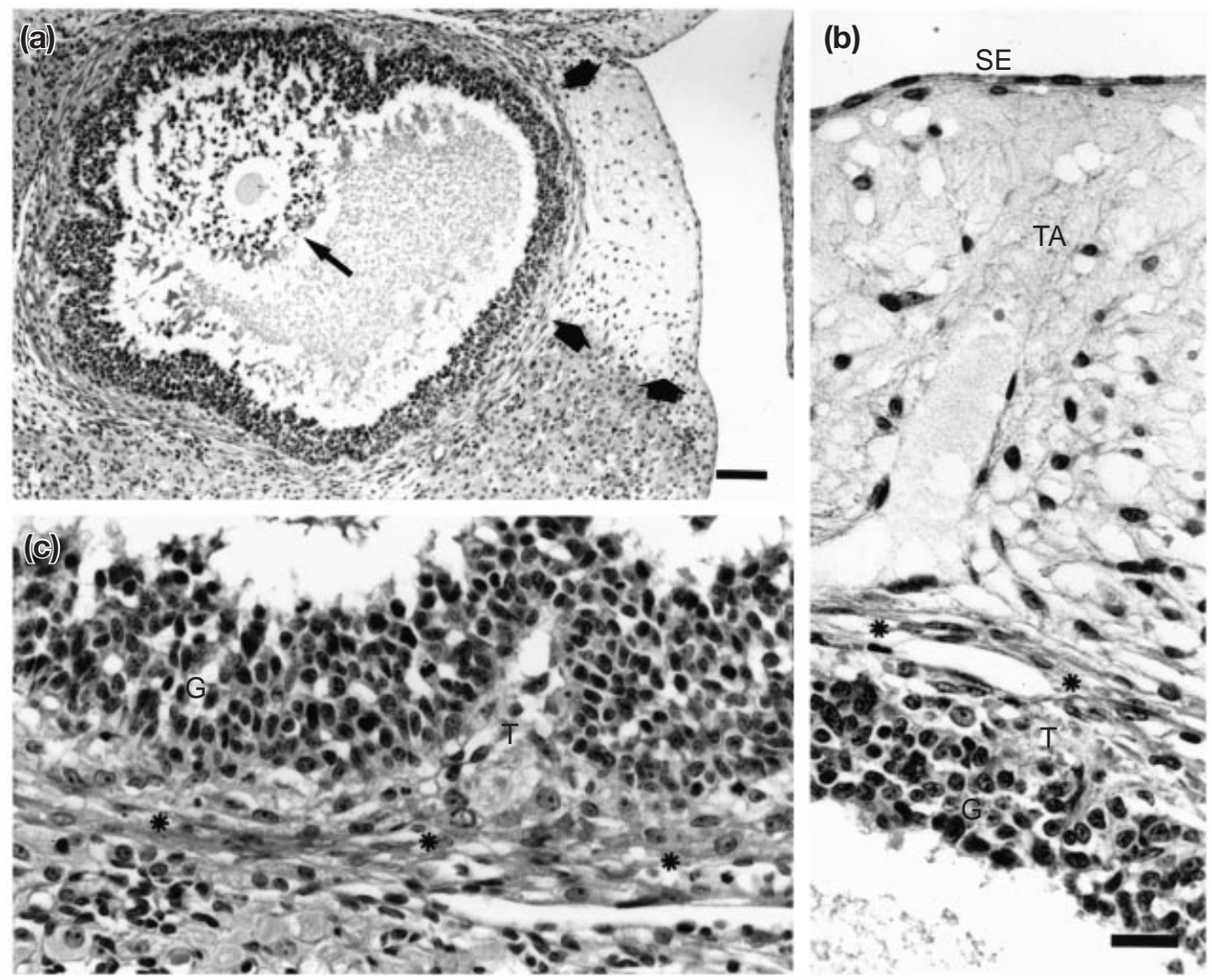

Fig. 2. (a) Preovulatory follicle from a vehicle-treated rat, at $02: 00 \mathrm{~h}$ in oestrus, showing a dispersed cumulus (large arrow) and the oocyte in the telophase I stage. Oedema and loosening of the tunica albuginea and the ovarian stroma at the apex of the follicle (short arrows). (b) Detail of the apical zone of the follicle, showing the granulosa $(\mathrm{G})$, theca interna (T), theca externa (asterisks), tunica albuginea (TA) and surface epithelium (SE). (c) Detail of the base of the follicle, showing the morphology of the granulosa (G), theca interna (T), and theca externa (asterisks) layers. Scale bars represent (a) 80 and (b,c) $50 \mu \mathrm{m}$.

cavity, surrounded by the corona radiata cells and was in telophase I, showing formation of the first polar body (Fig. 2a). The theca cell layer showed infoldings and vascular congestion (Fig. 2). The granulosa cell layer was somewhat disorganized, and oedema and loosening of the connective tisue of the tunica albuginea and underlying ovarian stroma, with increased extracellular space, was observed at the apex of the follicle (Fig. 2a,b).

In mature follicles of indomethacin-treated rats, maturational changes at the cumulus and resumption of the meiotic process were equivalent to those of control rats (Fig. 3a). However, large differences were found at the follicle wall. Oedema and loosening of connective tissues at the apex of the follicle were not detectable (Fig. 3a). The limits between the granulosa and theca layers were indistinct and granulosa cells were invading the theca layer (Fig. 3b,c). Some granulosa cells showed elongated nuclei and were in contact with the interstitial tissue (Fig. 3c). Serial sections demonstrated that invasion of the theca layer ocurred at several points of the follicle wall. A variable number of follicles (from 20 to 50\%) had completed follicle rupture, and granulosa cells and follicular fluid went across a gap in the theca layer, invading the ovarian interstitium (Fig. 4a-d). In some follicles, the cumulus containing the oocyte was also found in the interstitium (Fig. 4e). A small number of follicles (from 5 to 20\%) showed rupture at the ovarian surface (Fig. 5a). In some of these follicles, a large area of the ovarian surface had been degraded (Fig. 5b).

On the morning (09:00 h) of oestrus, control rats had newly formed corpora lutea that were not fully luteinized, and oocytes (in metaphase II) were found in the oviducts. In indomethacin-treated rats, follicles showed variable features. In some cases, the oocyte (in metaphase II) was retained in the follicular antrum. However, in these follicles, escape of granulosa cells and leakage of follicular fluid through gaps in the theca layer were observed, at several sites of the follicle wall (Fig. 6a). In other cases, the oocyte surrounded by granulosa cells was found in interstitial lacunae (Fig. 6b). Leucocyte margination was observed in the surrounding blood vessels (Fig. 6b). Some follicles that were ruptured at the ovarian surface had nearly normal features, although some rupture points were observed 


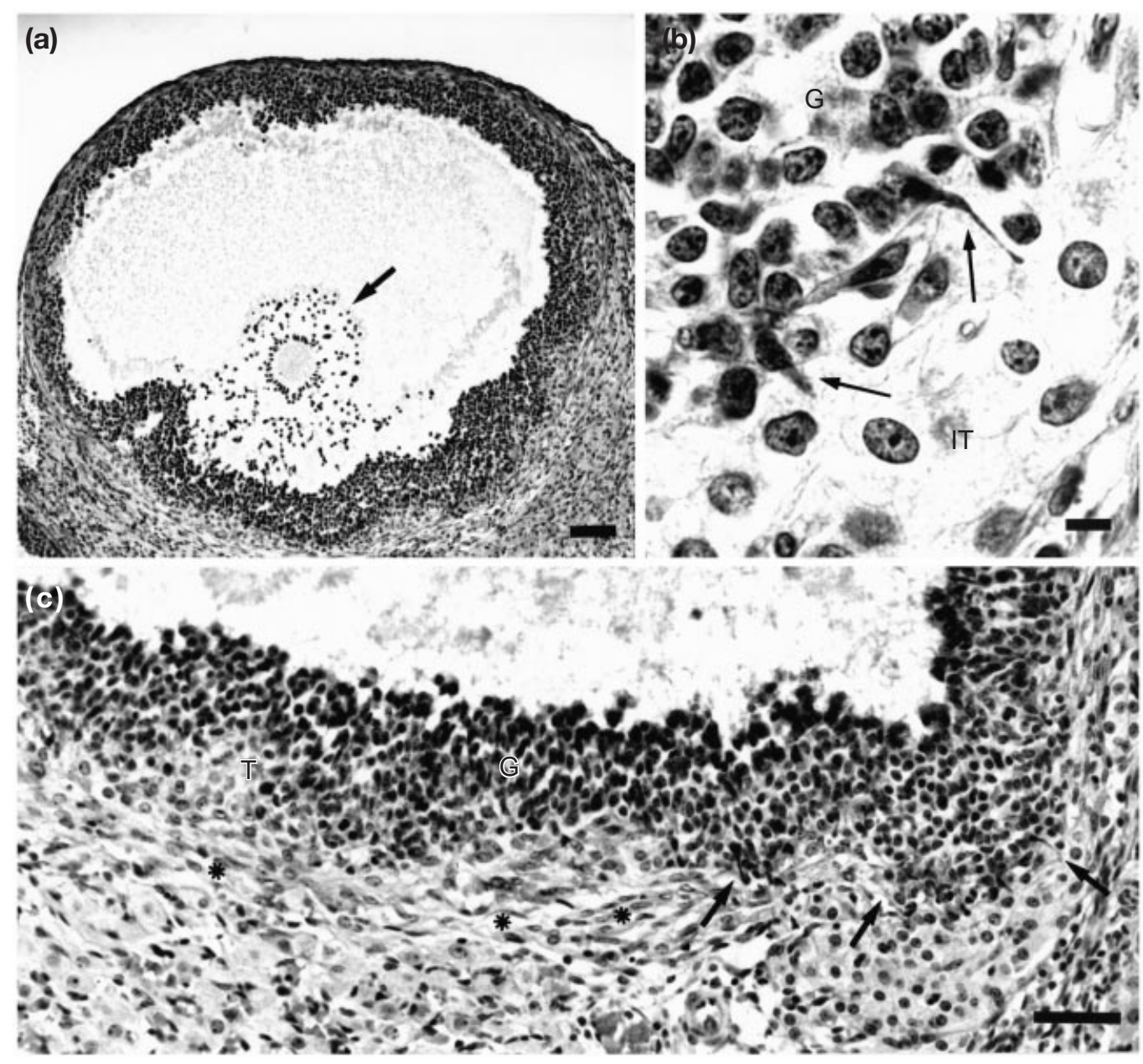

Fig. 3. (a) Mature follicle from a rat treated with $1.0 \mathrm{mg}$ indomethacin at $02: 00 \mathrm{~h}$ in oestrus, showing dispersion of the cumulus (arrow) and the absence of loosening of the apex. (b) Higher magnification of the base of the follicle. In some areas (arrows), cells of the granulosa layer $(\mathrm{G})$ are invading the theca interna $(\mathrm{T})$ and the theca externa (asterisks). (c) Detail of an area of (b) in which elongated granulosa cells (arrows) contact with the interstitial tissue (IT). Scale bars represent (a) 80, (b) 70 and (c) $8 \mu \mathrm{m}$.

in the border of the corpus luteum. Some oocytes were found in the oviducts. The most relevant feature at this time was the invasion of blood vessels by granulosa cells and follicular fluid. Although signs of blood vessel invasion were already apparent in some follicles at 02:00 $\mathrm{h}$ in oestrus (Fig. 4e), this process was evident at 09:00 $\mathrm{h}$ in oestrus. Granulosa cells and follicular fluid eroded the blood vessel wall and produced emboli that were surrounded by polymorphonuclear leucocytes (Fig. 7). Emboli of granulosa cells and follicular fluid were observed not only close to the point of rupture of the follicles (Fig. 7a-d), but also at a distance, in central veins of the ovarian medula (Fig. 7e). All the above described characteristics were observed with all three doses of indomethacin used. Quantitative data at 09:00 $\mathrm{h}$ in oestrus are presented (Table 1). More than 90\% of luteinized follicles showed points of rupture of the wall. In about $44 \%$ of these follicles, the oocyte was entrapped, whereas in about $35 \%$ of the follicles, the oocyte was found in the interstitium. In about $16 \%$ of the follicles, the oocyte had been released to the periovarian space. In a small percentage of follicles $(<8 \%)$, rupture points were not observed. Significant differences were not found for the different doses of indomethacin. The relationship between oocyte location and the distribution of rupture sites in indomethacin-treated rats is presented (Fig. 8). Most luteinized follicles-corpora lutea in which the oocyte was entrapped, and about half of those in which the oocyte was released to the interstitium, showed several rupture sites on the basolateral or apical sides.

On the evening (19:00 $\mathrm{h}$ ) of oestrus, and on the morning (09:00 h) of metoestrus, control rats had well vascularized, luteinized corpora lutea. In indomethacin-treated rats, corpora lutea were also well vascularized and luteinized, irrespective of the presence or absence of an antral cavity. Oocytes were observed either inside corpora lutea or in the ovarian interstitium (Fig. 9a). Clumps of luteinized granulosa 

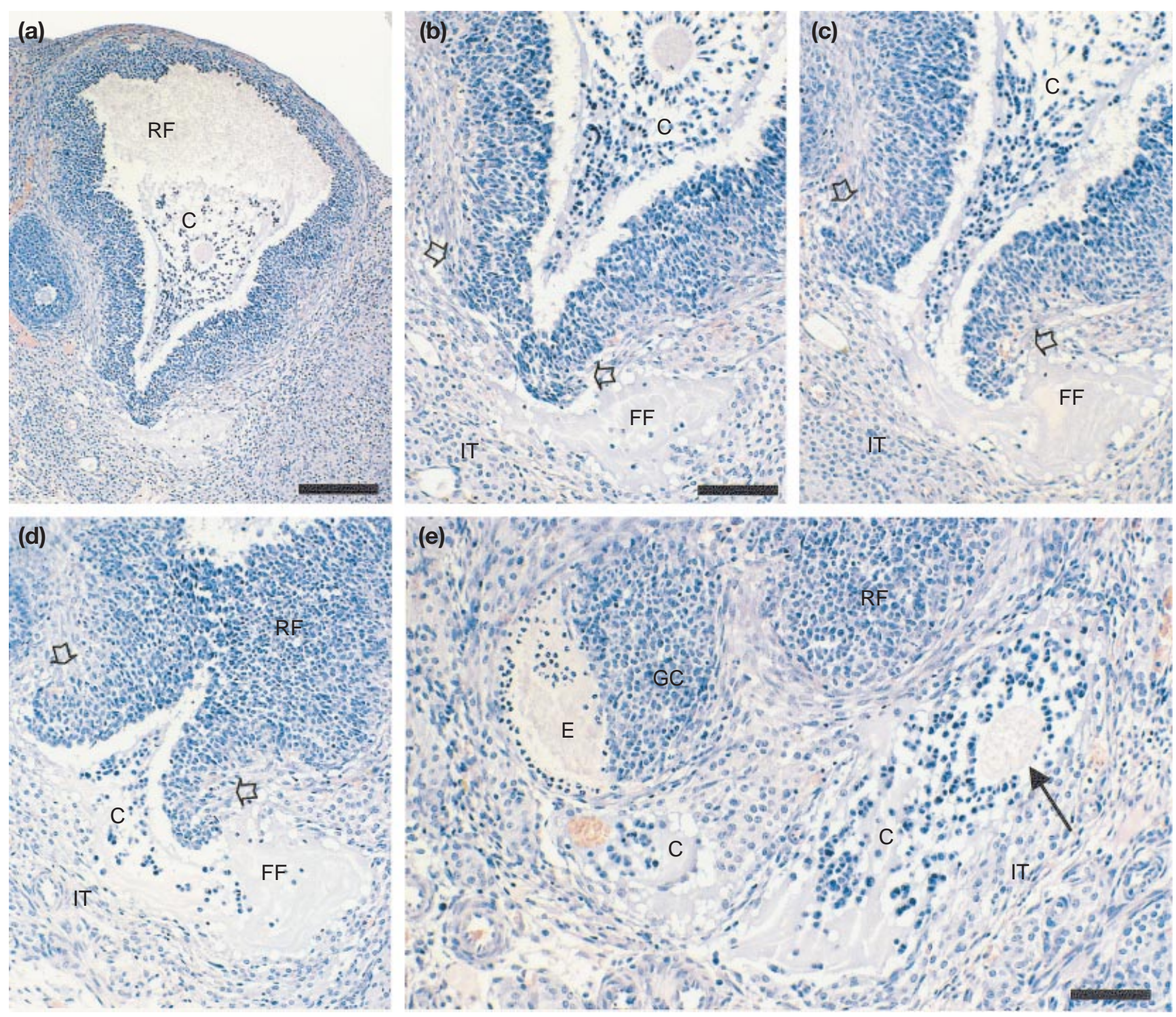

Fig. 4. Rupturing follicles from rats treated with $1.0 \mathrm{mg}$ indomethacin at $02: 00 \mathrm{~h}$ in oestrus. (a-d) Non-consecutive serial sections from a rupturing follicle (RF). Most of the cumulus (C) containing the oocyte is inside the follicle, but folliclular fluid (FF) can be observed in the interstitium (IT). The rupture points in the theca are indicated by arrows. (e) Ruptured follicle (RF). The cumulus (C) containing the oocyte (arrow) can be observed in the interstitium (IT), as can an embolus (E) of folliclular fluid and granulosa cells (GC), surrounded by polymorphonuclear leucocytes. Scale bars represent (a) 300, (b-d) 150 and (e) $80 \mu \mathrm{m}$.

cells, surrounded by inflammatory cells were observed (Fig. 9a) in the vicinity of some corpora lutea. In blood vessels containing entrapped emboli, there were inflammatory cells around vessel walls. Granulosa cells, when present in emboli, were luteinized and had rounded nuclei and prominent nucleoli (Fig. 9b).

\section{Discussion}

The proteolytic cascade, which is ultimately responsible for follicle rupture, should be tightly controlled, spatially targeted, and time limited, to assure efficient release of eggs and to prevent potential damage to the perifollicular ovarian tissues. Several studies have focused on the presence of different types of proteolytic activity and on its possible involvement in the ovulation. Increases in the activities of kalikrein (Espey et al., 1989), plasminogen activator (Reich et al., 1985b; Chun et al., 1992; Hägglund et al., 1996) and matrix metalloproteinase (Curry et al., 1985, 1986; Reich et al., 1991; Liu et al., 1998; Curry and Osteen, 2001) have been demonstrated in the ovary during ovulation. These proteolytic activities are counteracted by the expression of different antiproteinases, such as plasminogen activator inhibitors (PAl-1 and -2) and tissue inhibitors of 


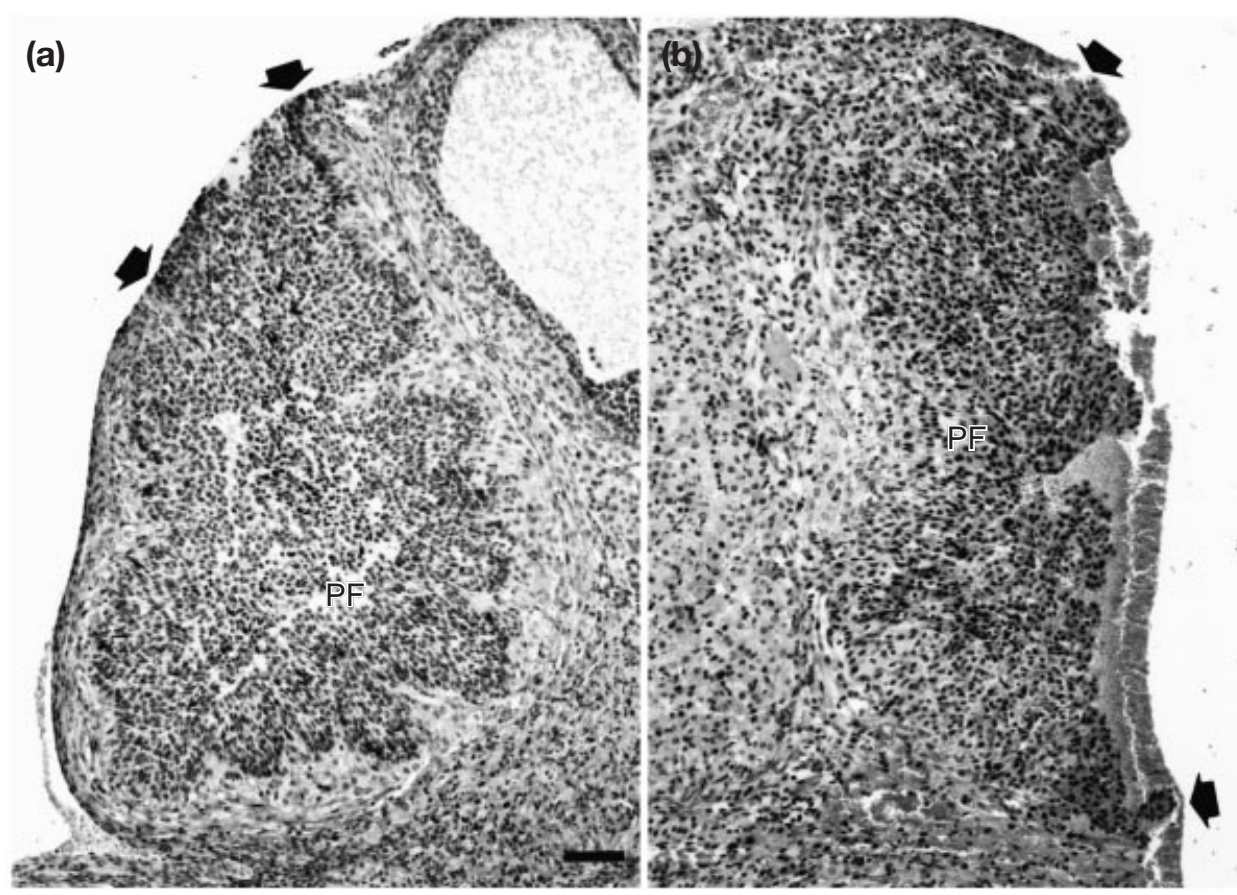

Fig. 5. (a,b) Postovulatory follicles (PF) at $02: 00 \mathrm{~h}$ in oestrus from rats injected with $1.0 \mathrm{mg}$ indomethacin. The margins of the rupture area at the ovarian surface are indicated by arrows. Scale bar represents $80 \mu \mathrm{m}$.

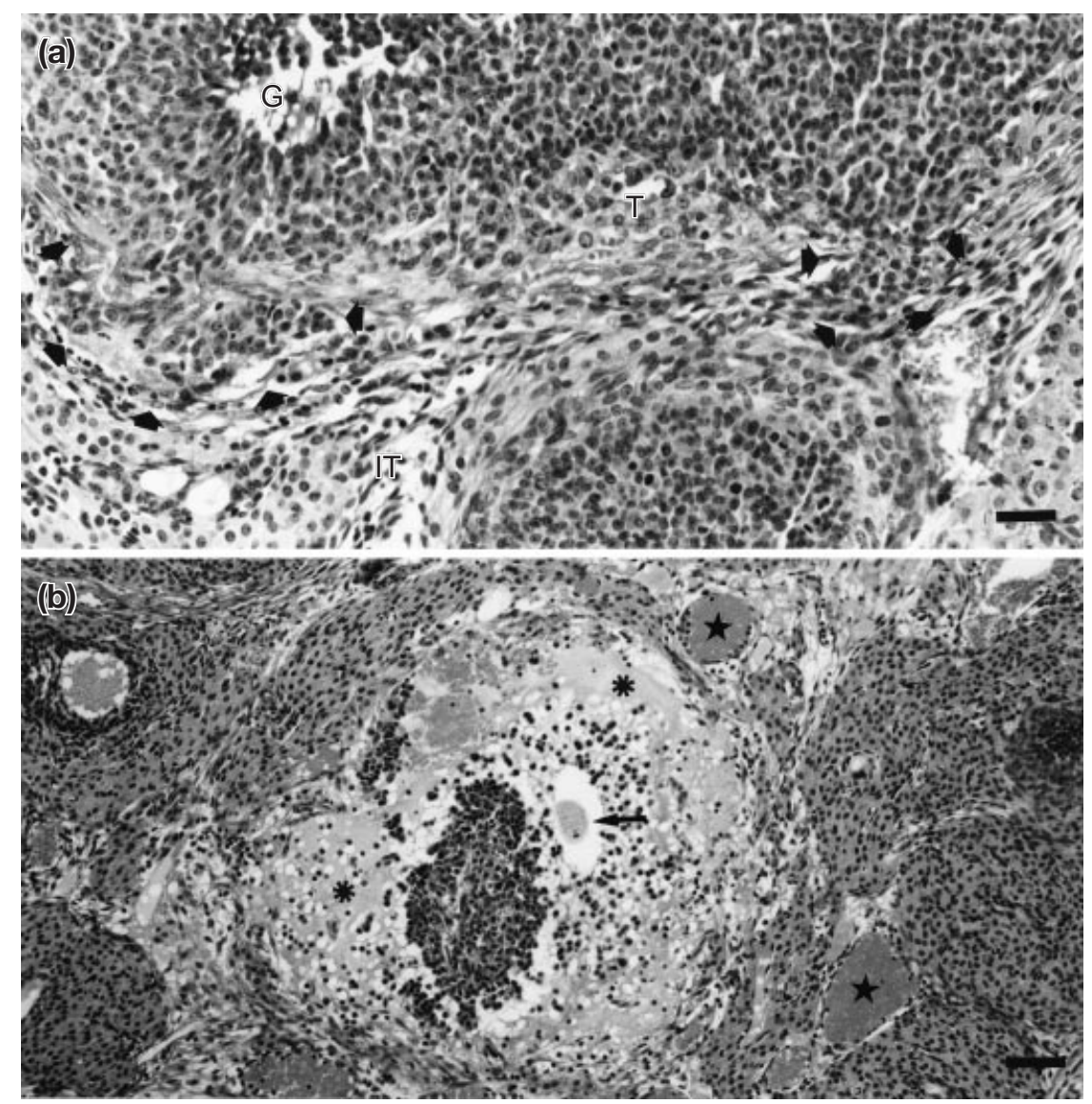

Fig. 6. For legend see facing page. 

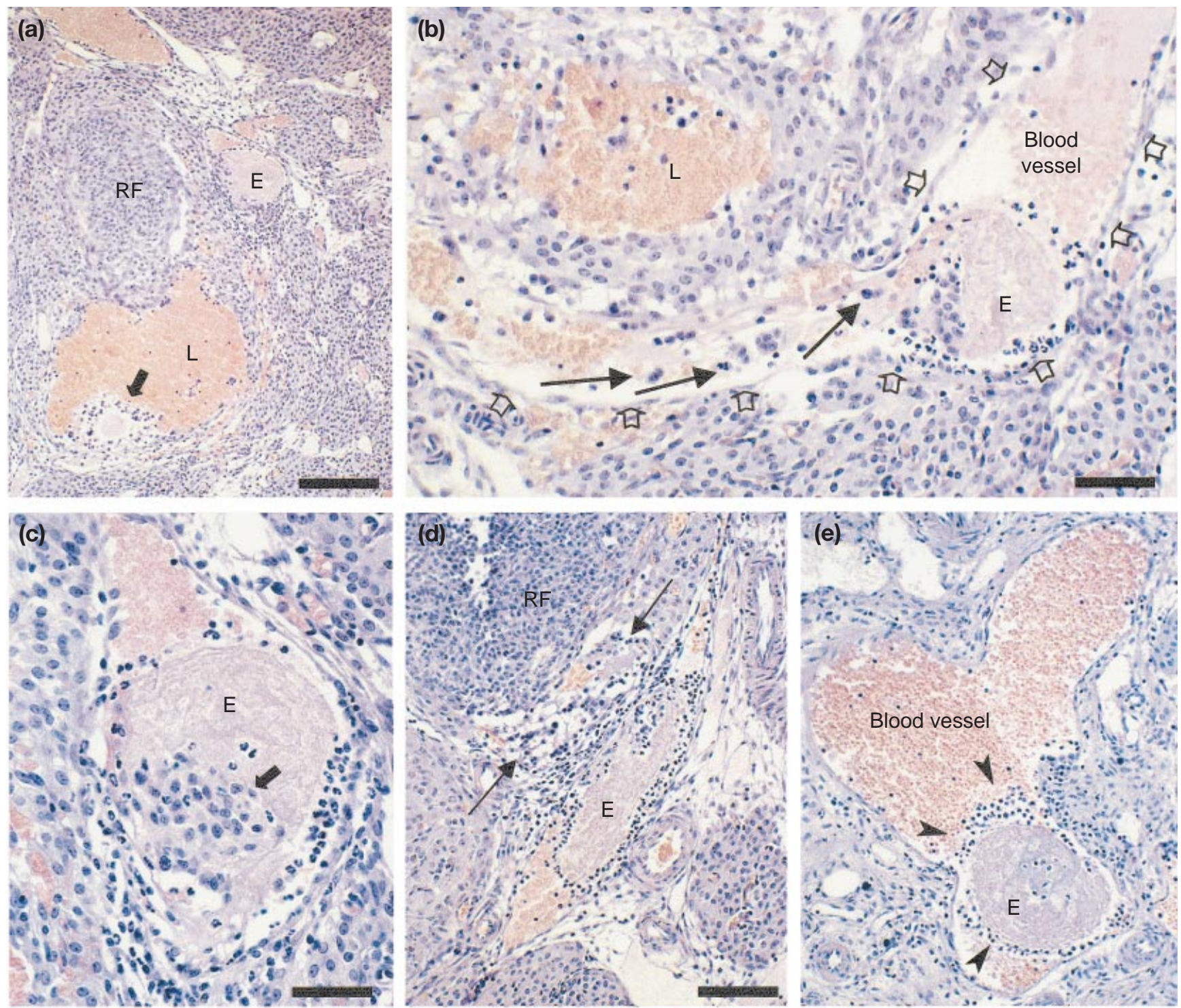

Fig. 7. Micrographs from indomethacin-treated rats at 09:00 $\mathrm{h}$ in oestrus showing invasion of blood vessels and embolus formation. $(\mathrm{a}-\mathrm{c})$ Non-consecutive serial sections of a ruptured follicle (RF) from a rat injected with $4.0 \mathrm{mg}$ indomethacin. (a) The oocyte (arrow) is located in an interstitial lacuna (L) filled with blood. An embolus (E) can be also observed. (b) Granulosa cells (long arrows) and embolus (E) of granulosa cells and follicular fluid, inside a blood vessel. The vessel wall is indicated by short arrows. (c) Detail of an embolus (E) containing granulosa cells (arrow). (d) Invasion of a blood vessel by granulosa cells (arrows) and formation of an embolus (E) in a rat treated with $1.0 \mathrm{mg}$ indomethacin. (e) Embolus (E), surrounded by polymorphonuclear leukocytes (arrowheads) in a blood vessel of the ovarian medulla, from a rat injected with $1.0 \mathrm{mg}$ indomethacin. Scale bars represent (a) 400, (b) 80, (c) 70 and (d,e) $150 \mu \mathrm{m}$.

metalloproteinases (TIMPs) (Curry et al., 1990; Reich et al., 1991; Zhu and Woessner, 1991; Chun et al., 1992; Hägglund et al., 1996; Curry and Osteen, 2001).

The present study documents follicle rupture in all indomethacin-treated rats, in agreement with the report of Osman and Dullaart (1976) that oocytes are released from adjacent luteinized follicles on the morning of oestrus. In the present study, disruption of the theca layers, invasion of the perifollicular tissue by granulosa cells and follicular fluid, rupture of blood vessel walls, and production of emboli of granulosa cells and follicular fluid were observed. These findings are the result of the proteolytic degradation of extracellular matrix and basement membranes, and constitute indirect, but unequivocal, evidence of uncon-

Fig. 6. Micrographs from rats injected with $0.5 \mathrm{mg}$ indomethacin, at 09:00 $\mathrm{h}$ in oestrus. (a) In a follicle that contained the oocyte, cells of the granulosa (G) layer invade the interstitial tissue (IT) in several areas (arrows). (b) The oocyte (arrow), together with granulosa cells, in the ovarian interstitium (asteriks), and leucocyte margination in the surrounding blood vessels (stars). Scale bars represent (a) 50 and (b) $200 \mu \mathrm{m}$. 
Table 1. Mean \pm SEM percentages of the different types of luteinized follicles-corpora lutea on the morning of oestrus in rats treated with indomethacin

\begin{tabular}{lcccc}
\hline & \multicolumn{4}{c}{ Dose of indomethacin (number of rats) } \\
\cline { 2 - 5 } Type of luteinized follicle & $0.0 \mathrm{mg}(5)$ & $0.5 \mathrm{mg}(5)$ & $1.0 \mathrm{mg}(5)$ & $4.0 \mathrm{mg}(3)$ \\
\hline $\begin{array}{l}\text { Unruptured } \\
\text { Ruptured }\end{array}$ & - & $7.7 \pm 5.1$ & $2.9 \pm 2.3$ & $6.4 \pm 4.5$ \\
$\quad$ Oocyte released to peri-ovarian space & 100 & $16.7 . \pm 3.1$ & $13.1 \pm 1.7$ & $19.4 \pm 5.2$ \\
$\quad \begin{array}{l}\text { Oocyte released to interstitium } \\
\text { Oocyte retained inside follicle }\end{array}$ & - & $36.9 \pm 7.7$ & $41.7 \pm 13.1$ & $29.1 \pm 14.8$ \\
\hline
\end{tabular}

Differences in terms of the dose of indomethacin were not signficiant (ANOVA and Tukey's test).

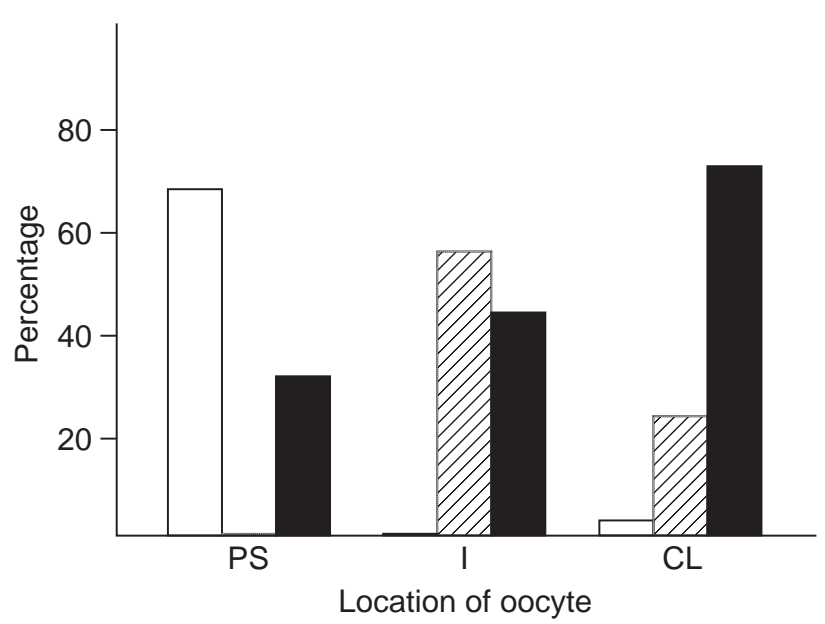

Fig. 8. Relationships between the location of oocyte and rupture sites in ruptured luteinized follicles-corpora lutea in indomethacin treated-rats at 09:00 $\mathrm{h}$ in oestrus. Luteinized follicles-corpora lutea were classified into three types, depending on the location of the oocyte (PS: oocyte released to periovarian space; I: oocyte released to interstitium; and CL: oocyte retained inside follicle), and into three classes, depending on the site of rupture ( $\square$ : class A, showing only one rupture site at the apex; $\square$ : class $B$, showing only one rupture site at the basolateral side; and $\mathbf{\square}$ : class $C$, showing several rupture sites at the basolateral side, possibly including a rupture site at the apex). Twenty-five luteinized follicles-corpora lutea of each type were scored, irrespective of the dose of indomethacin.

trolled proteolytic activity. These findings are in agreement with previous functional studies indicating that indomethacin does not interfere with proteolytic activities, such as those of plasminogen activator (Shimada et al., 1983; Tanaka et al., 1992) or collagenase (Curry et al., 1986).

The process of follicle rupture observed in indomethacintreated rats was altered in several ways. First, tissue degradation occurred earlier in indomethacin-treated than it did in control rats. This degradation was not likely to have been the result of an advanced preovulatory gonadotropin surge, as evidenced by the equivalent LH concentrations at $18: 30 \mathrm{~h}$ on the evening of proestrus (the expected time of the preovulatory LH surge in our colony; Gaytán et al., 1997a) and by the synchronism in the meiotic process of the oocyte that follows a well established sequence after the
LH surge (Vermeiden and Zeilmaker, 1974). Furthermore, in indomethacin-treated rats, invasion of blood vessels seemed to continue some time after follicle rupture, whereas, in control rats, tissue degradation appeared to be finished after ovulation. This finding indicates that proteolytic enzyme activation lasts longer in indomethacintreated rats.

Second, tissue degradation in indomethacin-treated rats was not limited to the apex of the follicle. Only a limited number of follicles (about 16\%) showed rupture at the ovarian surface. Serial sections demonstrated that disruption of the theca and follicular fluid leakage occur at several points in the follicle wall, and the release of the oocyte seemed to occur at random, probably through the most advanced of these rupture points. This contention may explain the repeatedly reported presence of a limited number of oocytes in the oviducts, even with the higher indomethacin doses (Espey et al., 1986, 1989; Tanaka et al., 1989; present study) even though this drug inhibits ovulation in a dose-dependent manner (Murdoch and McCormick 1991; Tanaka et al., 1992). Mice with targeted deletion of the prostaglandin synthase 2 gene that display ovulation impairment, also ovulated a limited number of ova (Russell and Richards, 1997). At least some of the inconsistencies in the literature, with respect to the mechanisms of the antiovulatory effects of indomethacin, may be the result of the fact that the absence of oocytes in the oviducts does not provide valuable information about whether follicle rupture has occurred.

Third, early vascular changes (such as oedema and loosening of the tunica albuginea and the underlying ovarian stroma), observed at the apex of preovulatory follicles in control rats, were not visible in indomethacintreated rats. Similar changes were reported by Downs and Longo $(1982,1983)$ in indomethacin-treated mice. Although oedema of the collagenous tissue at the apex of the follicle was not present in indomethecin-treated rats, follicle rupture at the apex did occur in $15-20 \%$ of follicles. This finding indicates that these changes are not an absolute requirement for follicle rupture, at least in indomethacintreated rats. However, these changes presumably facilitate follicle rupture at the apex in control rats (Espey and Lipner, 1994; Espey, 1998). 

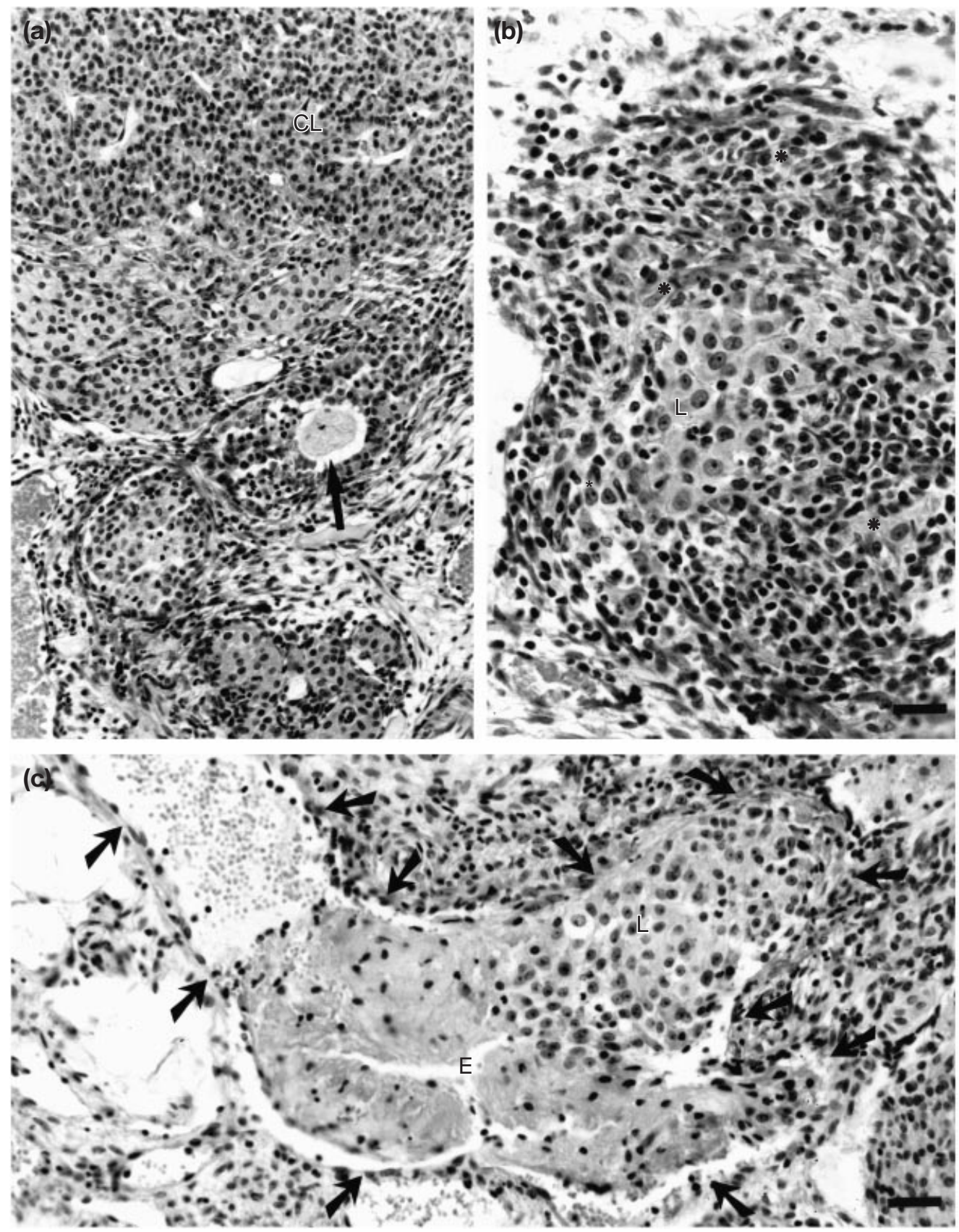

Fig. 9. Micrographs from rats injected with $1.0 \mathrm{mg}$ indomethacin (a) at 19:00 $\mathrm{h}$ in oestrus and $(\mathrm{b}, \mathrm{c})$ at 09:00 h in metoestrus. (a) Oocyte (arrow) surrounded by granulosa cells in the ovarian interstitium near to a corpus luteum (CL). (b) Luteinized granulosa cells (L) in the ovarian interstitium, surrounded by inflammatory cells (asterisks). (c) Embolus (E) containing luteinized granulosa cells (L). The vessel wall is indicated by arrows. Scale bars represent (a,c) 40 and (b) $30 \mu \mathrm{m}$.

Otherwise, oocytes were frequently retained inside the follicle, in spite of the gaps that occurred in the theca layer. There may be several reasons for this retention of oocytes. Intrafollicular pressure appears to play an important role in oocyte release (Espey, 1998). However, when rupture occurs at the sides or the base of the follicle, the pressure gradient with respect to the dense interstitial tissue should be lower than it is with respect to the periovarian space. Furthermore, loss of granulosa cells and leakage of follicular fluid through small gaps in the follicle wall should decrease pressure in the follicular antrum. In addition, creating passageways through the dense ovarian stroma wide enough to allow release of the mucified cumulus containing the oocyte seemed not to be achieved in some follicles. 
However, most of the luteinized follicles in which the oocyte was entrapped showed several rupture sites.

The results of the present study facilitate the proposal of a 'working hypothesis' about the mechanisms of the antiovulatory effects of indomethacin and the possible role of prostanoids in ovulation. The $\mathrm{LH}$-initiated release of matrixdegrading enzymes by granulosa cells is counteracted by the release of proteinase inhibitors. The balance between activators and inhibitors of proteinase activity is tilted toward inhibition throughout the follicle wall, and prostanoids have a key role in maintaining this proteolytic inhibition. Under physiological conditions, the balance between proteolytic and antiproteolytic factors is tilted toward proteolysis at the apex of the follicle, probably by the release of activating factors by the tunica albuginea or the ovarian surface epithelium. In this context, the main effect of indomethacin seems to be the disruption of the inhibition of proteinase activity throughout the follicle wall, which is probably achieved by inhibiting the synthesis of one or more ovarian prostanoids. However, the existence of prostanoid-independent effects cannot be discarded. Indomethacin has effects on other mechanisms, such as $\mathrm{Ca}^{2+}$ flux (Burch et al., 1983; Murdoch, 1996), which is involved in many physiological processes. Therefore, the effects of indomethacin on ovulation may be exerted through inhibition of $\mathrm{Ca}^{2+}$ flux. Further studies comparing the effects of indomethacin with those of other prostaglandin synthesis inhibitors that do not inhibit $\mathrm{Ca}^{2+}$ flux (Burch et al., 1983), as well as prostanoid replacement studies, are needed before definitive conclusions can be drawn.

The authors are very grateful to J. Molina for excellent technical assistance. This work has been subsidized by Grants 1FD97-1065CO3-03 and PM98-0167 from the DGESEIC, Spain.

\section{References}

Brännström M and Janson PO (1991) The biochemistry of ovulation. In Ovarian Endocrinology pp 132-166 Ed. SG Hillier. Blackwell Scientific Publications, Oxford

Burch RM, Curtis W and Halushka V (1983) Prostaglandin-independent inhibition of calcium transport by nonsteroidal anti-inflammatory drugs: differential effects of carboxylic acids and piroxicam Journal of Pharmacological and Experimental Therapeutics 227 84-91

Chun SY, Popliker M, Reich R and Tsafriri A (1992) Localization of preovulatory expression of plasminogen activator inhibitor type- 1 and tissue inhibitor of metalloproteinase type- 1 mRNAs in the rat ovary Biology of Reproduction 47 245-253

Curry TE, Jr and Osteen KG (2001) Cyclic changes in the matrix metalloproteinase system in the ovary and uterus Biology of Reprouction 64 1285-1296

Curry TE, Jr, Dean DD, Woessner JE, Jr and LeMarie WJ (1985) The extraction of a tissue collagenase associated with ovulation in the rat Biology of Reproduction 33 981-991

Curry TE, Jr, Clark MR, Dean DD, Woessner JF, Jr and LeMarie WJJ (1986) The preovulatory increase in ovarian collagenase activity in the rat is independent of prostaglandin production Endocrinology 118 1823-1828

Curry TE, Jr, Mann JS, Estes RS and Jones PBC (1990) $\alpha 2$-macroglubulin and tissue inhibitor of metalloproteinases: collagenase inhibitors in human preovulatory follicles Endocrinology 127 63-68
Downs SM and Longo FJ (1982) Effects of indomethacin on preovulatory follicle in immature, superovulated mice American Journal of Anatomy $164265-274$

Downs SM and Longo FJ (1983) An ultrastructural study of preovulatory apical development in mouse ovarian follicles: effects of indomethacin Anatomical Record 205 159-168

Espey LL (1980) Ovulation as an inflammatory reaction - a hypothesis Biology of Reproduction 22 73-106

Espey LL (1994) Current status of the hypothesis that mammalian ovulation is comparable to an inflammatory reaction Biology of Reproduction; 50 $233-238$

Espey LL (1998) Ovulation. In Encyclopedia of Reproduction 2nd Edn, Vol. 3, pp 605-614 Eds E Knobil and JD Neill. Academic Press, London

Espey LL and Lipner H (1994) Ovulation. In Physiology of Reproduction 2nd Edn, Vol. 3, pp 725-780 Eds E Knobil and JD Neill. Raven Press, New York

Espey LL, Coons PJ, Marsh JM and LeMarie WJ (1981) Effect of indomethacin on preovulatory changes in the ultrastructure of rabbit Graafian follicles Endocrinology 108 1040-1048

Espey LL, Norris C and Shapire D (1986) Effect of time and dose of indomethacin on follicular prostaglandins and ovulation in the rabbit Endocrinology $119746-754$

Espey LL, Tanaka N, Winn V and Okamura H (1989) Increase in ovarian kallikrein activity during ovulation in the gonadotropin-primed immature rat Journal of Reproduction and Fertility 87 503-508

Gaytán F, Bellido C, Morales C, Aguilar E and Sánchez-Criado JE (1997a) Follicular growth pattern in cycling rats from late pro-oestrus to early oestrus Journal of Reproduction and Fertility 110 153-159

Gaytán F, Bellido C, Morales C, Aguilar E and Sánchez-Criado JE (1997b) Proliferative activity of preovulatory follicles and newly formed corpora lutea in cyclung rats from late prooestrus to early oestrus Journal of Anatomy 191 425-430

Hägglund AC, Ny A, Liu K and Ny T (1996) Coordinated and cell-specific induction of both physiological plasminogen activators creates functionally redundant mechanisms for plasmin formation during ovulation Endocrinology137 5671-5677

Hamada Y, Bronson RA, Wright KH and Wallach EE (1977) Ovulation in the perfused rabbit ovary: the influence of prostaglandins and prostaglandin inhibitors Biology of Reproduction 17 58-63

Holmes PV, Janson PO, Sogn J, Källfelt B, LeMarie WJ, Ahrén KB, Cajander $\mathbf{S}$ and Bjersing L (1983) Effects of prostaglandin- $\mathrm{F}_{2 \alpha}$ and indomethacin on ovulation and steroid production in the isolated perfused rabbit ovary Acta Endocrinologica (Copenhagen) 104 233-239

Liu K, Wahlberg P and Ny T (1998) Coordinated and cell-specific regulation of membrane type matrix metalloproteinase 1 (MT1-MMP) and its substrate matriz metalloproteinase 2 (MMP-2) by physiological signals during follicular development and ovulation Endocrinology 139 4735-4738

Mikuni M, Yoshida M, Hellberg P, Peterson CA, Edwin SS, Brännström M and Peterson CM (1998) The lipooxygenase inhibitor, norhydroguaiaretic acid, inhibits ovulation and reduces leukotriene and prostaglandin levels in the rat ovary Biology of Reproduction 58 1211-1216

Murdoch WJ (1996) Differential effects of indomethacin on the sheep ovary: prostaglandin biosynthesis, intracellular calcium, apoptosis, and ovulation Prostaglandins 52 497-506

Murdoch WJ and McCormick RJ (1991) Dose-dependent effects of indomethacin on ovulation in the sheep: relationship to follicular prostaglandin production, steroidogenesis, collagenolysis, and leukocyte chemotaxis Biology of Reproduction 45 907-911

Osman P and Dullaart J (1976) Intraovarian release of eggs in the rat after indomethacin treatment at pro-oestrus Journal of Reproduction and Fertility 47 101-103

Parr EL (1974) Histological examination of the rat ovarian follicle wall prior to ovulation Biology of Reproduction 11 483-503

Reich R, Tsafriri A and Mechanic GL (1985a) The involvement of collagenolysis in ovulation in the rat Endocrinology 116 522-527

Reich R, Miskin R and Tsafriri A (1985b) Follicular plasminogen activator: involvement in ovulation Endocrinology 116 516-521

Reich R, Daphna-Iken D, Chun SY; Popliker M, Slager R, Adelmann-Grill 
BC and Tsafriri A (1991) Preovulatory changes in ovarian expression of collagenases and tissue metalloproteinase inhibitor messenger ribonucleic acid: role of eisosanoids Endocrinology 129 1869-1875

Russell DL and Richards JS (1997) Causes of infertility in mice with targeted deletion of the PGS-2 gene Biology of Reproduction Supplement $\mathbf{5 6} 178$ (Abstract 382)

Sánchez-Criado JE, Galiot F, Bellido C, Gónzalez D and Tebar M (1993) Hipothalamus-pituitary-ovarian axis in cycling rats lacking progesterone actions Biology of Reproduction 48 916-925

Shimada H, Okamura H, Noda Y, Suzuki A, Tojo S and Takada A (1983) Plasminogen activator in rat ovary during the ovulatory process: independence of prostaglandin mediation Journal of Endocrinology 97 201-205

Tanaka N, Espey LL and Okamura H (1989) Increase in ovarian 15hydroxyeicosa-tetraenoic acid during ovulation in the gonadotropinprimed immature rat Endocrinology 125 1373-1377

Tanaka N, Espey LL, Stacy S and Okamura H (1992) Epostane and indomethacin actions on ovarian kallikrein and plasminogen activator activities during ovulation in the gonadotropin-primed immature rats Biology of Reproduction $\mathbf{4 6}$ 665-670

Tsafriri A, Chun SY and Reich R (1993) Follicular rupture and ovulation. In The Ovary pp 228-243 Eds EY Adashi and PCK Leung. Raven Press, New York

Vermeiden JPW and Zeilmaker GH (1974) Relationship between maturation division, ovulation and luteinization in the female rat Endocrinology 95341-351

Zhu C and Woessner JF (1991) A tissue inhibitor of metalloproteinases and $\alpha$-macroglobulins in the ovulating rat ovary: possible regulators of collagen matrix breakdown Biology of Reproduction 45 334-342

Received 10 September 2001.

First decision 3 December 2001

Revised manuscript received 17 December 2001.

Accepted 17 January 2002. 